\title{
Recent Electric Propulsion Development Activities for NASA Science Missions
}

\author{
Eric J. Pencil \\ NASA Glenn Research Center \\ Cleveland, Ohio 44135 \\ 216-977-7463 \\ Eric.J.Pencil@nasa.gov
}

Abstract-The primary source of electric propulsion development throughout NASA is managed by the In-Space Propulsion Technology Project at the NASA Glenn Research Center for the Science Mission Directorate. The objective of the Electric Propulsion project area is to develop near-term electric propulsion technology to enhance or enable science missions while minimizing risk and cost to the end user. Major hardware tasks include developing NASA's Evolutionary Xenon Thruster (NEXT), developing a long-life High Voltage Hall Accelerator (HIVHAC), developing an advanced feed system, and developing crossplatform components. The objective of the NEXT task is to advance next generation ion propulsion technology readiness. The baseline NEXT system consists of a highperformance, 7-kW ion thruster; a high-efficiency, 7-kW power processor unit (PPU); a highly flexible advanced xenon propellant management system (PMS); a lightweight engine gimbal; and key elements of a digital control interface unit (DCIU) including software algorithms. This design approach was selected to provide future NASA science missions with the greatest value in mission performance benefit at a low total development cost. The objective of the HIVHAC task is to advance the Hall thruster technology readiness for science mission applications. The task seeks to increase specific impulse, throttle-ability and lifetime to make Hall propulsion systems applicable to deep space science missions. The primary application focus for the resulting Hall propulsion system would be cost-capped missions, such as competitivelyselected, Discovery-class missions. The objective of the advanced xenon feed system task is to demonstrate novel manufacturing techniques that will significantly reduce mass, volume, and footprint size of xenon feed systems over conventional feed systems. This task has focused on the development of a flow control module, which consists of a three-channel flow system based on a piezo-electrically actuated valve concept, as well as a pressure control module, which will regulate pressure from the propellant tank. Cross-platform component standardization and simplification are being investigated through the Standard Architecture task to reduce first user costs for implementing electric propulsion systems. Progress on current hardware development, recent test activities and future plans are discussed. $^{12}$

\footnotetext{
1

${ }^{1}$ U.S. Government work not protected by U.S. copyright.

${ }^{2}$ IEEEAC paper \# 1628, Version 2, Updated January 9, 2009
}

TABLE OF CONTENTS

NOMENCLATURE ........................................................................... 1

1. INTRODUCTION ........................................................................ 2

2. NASA'S EVOLUTIONARY XENON THRUSTER (NEXT) ION PROPULSION SYSTEM ..................................................2

3. High Voltage Hall ACCElERator (HIVHAC)

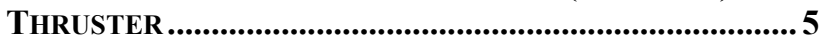

4. ADVANCED XENON FEED SYSTEM (AXFS) ....................... 6

5. STANDARD ARCHITECTURE .............................................. 7

6. CONCLUSIONS ............................................................................. 7

ACKNOWLEDGMENTS...................................................... 7

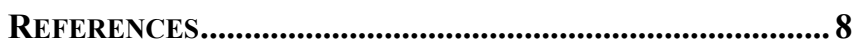

BIOGRAPHY ...........................................................................

\section{NOMENCLATURE}

$\begin{array}{ll}\text { ASOA } & =\text { Advanced State-Of-Art } \\ \text { AXFS } & =\text { Advanced Xenon Feed System } \\ \text { DCA } & =\text { Discharge Cathode Assembly } \\ \text { DCIU } & =\text { Digital Control Interface Unit } \\ \text { EM } & =\text { Engineering Model } \\ \text { FCM } & =\text { Flow Control Module } \\ \text { GRC } & =\text { Glenn Research Center } \\ \text { HIVHAC } & =\text { High Voltage Hall Accelerator } \\ \text { HPA } & =\text { High Pressure Assembly } \\ \text { IPS } & =\text { Ion Propulsion System } \\ \text { ISPT } & =\text { In-Space Propulsion Technology } \\ \text { JPL } & =\text { Jet Propulsion Laboratory } \\ \text { LDT } & =\text { Long Duration Test } \\ \text { LPA } & =\text { Low Pressure Assembly } \\ \text { mN } & =\text { milli-Newton } \\ \text { MTAT } & =\text { Multi-Thruster Array Test } \\ \text { NCA } & =\text { Neutralizer Cathode Assembly } \\ \text { NEXT } & =\text { NASA's Evolutionary Xenon Thruster } \\ \text { NSTAR } & =\text { NASA's Solar Electric Propulsion } \\ & \text { Technology Application Readiness } \\ \text { PAT } & =\text { Performance Assessment Test } \\ \text { PCM } & =\text { Pressure Control Module } \\ \text { PM } & =\text { Prototype Model } \\ \text { PMS } & =\text { Propellant Management System } \\ \text { PPU } & =\text { Power Processor Unit } \\ \text { SMD } & =\text { Science Mission Directorate } \\ \text { SOA } & =\text { State-Of-Art } \\ \text { TRL } & =\text { Technology Readiness Level }\end{array}$




\section{INTRODUCTION}

NASA's Science Mission Directorate (SMD) conducts scientific exploration that is enabled by access to space. NASA's SMD is organized by mission themes that focus on investigations of the Earth, Sun, Solar System and Universe. The focus of solar system exploration is to extend humanity's presence throughout the solar system through robotic encounters to the other planets and their moons, to asteroids and comets, and to icy bodies in the outer reaches of our solar system. The progression of robotic missions is from observers to rovers to sample return missions. Each step brings us closer to the principal scientific goals: to understand our origins, to learn whether life does or did exist elsewhere in the solar system and to prepare for human expeditions to the Moon, Mars, and beyond.[1] Such ambitious goals exceed the capabilities provided by conventional technologies and will ultimately require improved spacecraft capabilities such as those obtained by advanced propulsion technologies.

Within SMD the In-Space Propulsion Technology (ISPT) Project is responsible for developing advanced propulsion capabilities to enable or to enhance science missions. NASA Glenn Research Center (GRC) is responsible for managing the ISPT Project for SMD. Recently ISPT has focused on the development of advanced chemical propulsion, aerocapture, and electric propulsion.[2] Investments in electric propulsion have focused on completing the NEXT ion propulsion system, a throttle-able gridded ion thruster propulsion system suitable for future Discovery, New Frontiers, and Flagship missions. In addition a novel Hall thruster concept is being developed to demonstrate a longlife, highly throttle-able thruster ideally suited for cost capped missions, like NASA Discovery missions. A novel feed system is being developed, which will significantly reduce the mass and size of future electric propulsion xenon feed systems. Cross-platform component standardization and simplification are being implemented through Standard Architecture activities to develop a digital control interface unit and simplified feed system. In addition to hardware development activities, ISPT performs mission analysis to assess system-level benefits in applying advanced propulsion technologies into robotic science missions.[3]

Electric propulsion is a technology area that is coming of age with application to a wide variety of applications. Over 200 recently launched spacecraft have incorporated electric propulsion, including commercial geosynchronous communication satellites and other deep space robotic science missions. One spacecraft of significance is the Dawn spacecraft, which was successfully launched in September 2007. This mission, enabled by the ion propulsion system, will investigate two of the heaviest main-belt asteroids; Vesta and Ceres.[4] Beyond the recent success in the U.S., other international, interplanetary science missions are using electric propulsion. The Japanese are using an ion propulsion system on Hayabusa, an asteroid sampling mission, while the Europeans have flown a hall propulsion system on SMART-1, a lunar reconnaissance mission.

ISPT has targeted technologies for near-term, robotic, interplanetary science missions. Given the mission constraints, like available spacecraft power and performance requirements, ISPT has focused on the development of electrostatic thrusters, such as ion thrusters and hall thrusters. This paper will elaborate on recent hardware development activities within the ISPT electric propulsion portfolio as well as recent progress toward technology infusion.

\section{NASA'S EvOLUTIONARY XENON THRUSTER (NEXT) ION PROPULSION SYSTEM}

\section{Description}

The objective of the NEXT project is to advance next generation ion propulsion technology readiness. As shown in Figure 1, the NEXT system consists of a highperformance, 7-kW ion thruster; a high-efficiency, 7-kW power processor unit (PPU); a highly flexible xenon propellant management system (PMS); a lightweight engine gimbal; and key elements of a digital control interface unit (DCIU) including software algorithms.[5-8] The NEXT team consists of NASA GRC as technology project lead, JPL as system integration lead, Aerojet as Prototype Model (PM) thruster, PMS, and DCIU simulator developer, and L3 Communications ETI as PPU developer. This design approach was selected to provide future NASA science missions with the greatest value in mission performance benefit at a low total development cost.

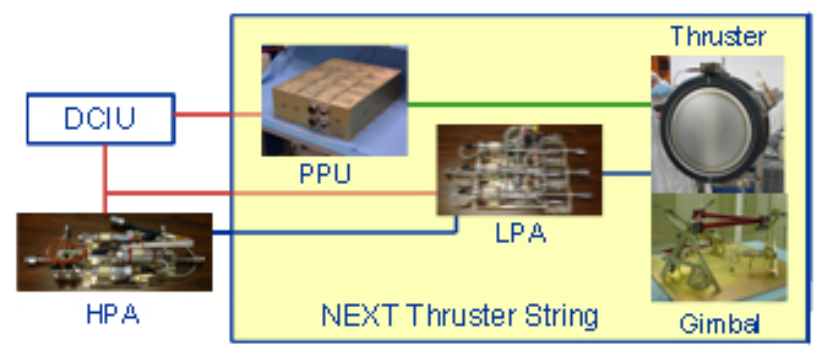

Figure 1 - NEXT Ion Propulsion System Components

The NEXT thruster and other component technologies represent a significant advancement in technology beyond state-of-art (SOA) NSTAR thruster systems. NEXT performance exceeds single or multiple NSTAR (NASA's Solar Electric Propulsion Technology Application Readiness) thrusters over most of the thruster input power range. Higher efficiency and specific impulse, and lower specific mass reduce the wet propulsion system mass and parts count. The NEXT thruster xenon propellant throughput capability is more than twice NSTAR's, so fewer thrusters are needed. The NEXT power processor and propellant feed system technologies provide specific mass and performance benefits versus SOA technology, which 
translate into better science capability for a given spacecraft or mission. Comparisons of NEXT and SOA NSTAR performance characteristics are listed in Table 1 . The NEXT development task has also placed particular emphasis on key aspects of ion propulsion system (IPS) development with the intention of avoiding the difficulties experienced by the Dawn mission in transitioning the NSTAR-based technology to an operational ion propulsion system.

Table 1. Performance Characteristics of NEXT vs. SOA Ion (NSTAR).

\begin{tabular}{|l|c|c|}
\hline \multicolumn{1}{|c|}{ Characteristic } & NEXT & SOA Ion \\
\hline Thruster Power Range, kW & $0.5-6.9$ & $0.5-2.3$ \\
\hline Throttle Ratio & $>12: 1$ & $4: 1$ \\
\hline Max. Specific Impulse, sec & $>4100$ & $>3100$ \\
\hline Max. Thrust, mN & 236 & 92 \\
\hline Max. Thruster Efficiency & $>70 \%$ & $>61 \%$ \\
\hline Propellant Throughput*, kg & $>300$ & 157 \\
\hline Specific Mass, kg/kW & 1.8 & 3.6 \\
\hline Max. PPU Efficiency & $94 \%$ & $92 \%$ \\
\hline PPU Specific Mass, kg/kW & 4.8 & 6.0 \\
\hline PMS Single-String Mass, kg & 5.0 & 11.4 \\
\hline
\end{tabular}

\section{Recent Progress}

The Prototype Model (PM1) thruster exhibited operational behavior consistent with its engineering model predecessors, but with substantial mass savings, enhanced thermal margins, and design improvements for environmental testing compliance.[9] A study of the thruster-to-thruster performance dispersions quantified a bandwidth of expected performance variations both on a thruster and a component level by compiling test results of five engineering model and one-flight-like model thrusters.[10] The thruster throughput capability was predicted to exceed $750 \mathrm{~kg}$ of xenon, an equivalent of 36,500 hours of continuous operation at full power.[11] The first failure mode for operation above a specific impulse of $2000 \mathrm{~s}$ is expected to be the structural failure of the ion optics at $750 \mathrm{~kg}$ of propellant throughput, 1.7 times the qualification requirement.[11] A review of life assessment predictions examining wear mechanisms at various throttle conditions was completed.[12] A LongDuration Test (LDT) was initiated to validate and qualify the NEXT propellant throughput capability to a qualification-level of $450 \mathrm{~kg}, 1.5$ times the mission-derived throughput requirement of $300 \mathrm{~kg}$. As of December 31 , 2008, the Engineering Model (EM) thruster has accumulated 19,556 hours of operation. An image of the LDT thruster in operation is shown in Figure 2. The thruster has processed $397 \mathrm{~kg}$ of xenon and demonstrated a total impulse of $1.54 \times 10^{7} \mathrm{~N}-\mathrm{s}$; the highest total impulse ever demonstrated by an ion thruster.[13] Test results have been recently published for the performance, plume, and wear characteristics. Thruster performance parameters including thruster, input power, specific impulse, and thruster efficiency have been nominal with little variation to date.[14] Thruster plume diagnostics and erosion measurements have been obtained periodically over the entire NEXT throttle table. Observed thruster component erosion rates are consistent with predictions and the thruster service life assessment.[15]

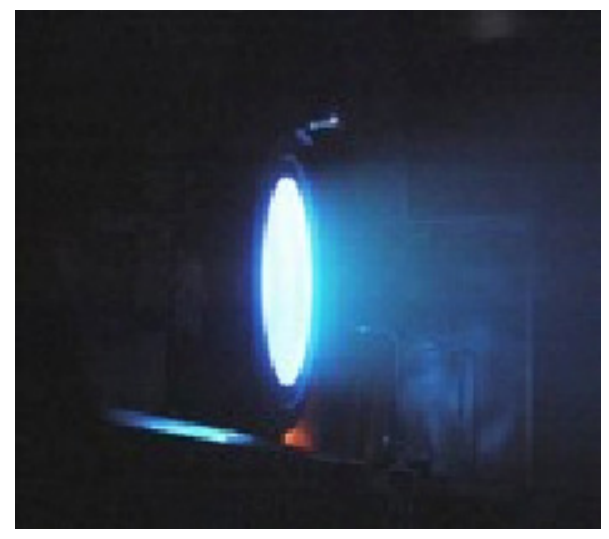

Figure 2 - NEXT EM3 Long Duration Test Thruster.

The PM1 thruster was subjected to qualification-level environmental testing to demonstrate compatibility with environments representative of anticipated mission requirements. Thruster functional testing was performed before and after the vibration and thermal-vacuum tests. Random vibration testing, conducted with the thruster mated to the breadboard gimbal was executed at $10.0 \mathrm{Grms}$ for two minutes in each of three axes. Thermal-vacuum testing included a deep cold soak of the engine to temperature of $168{ }^{\circ} \mathrm{C}$ and thermal cycling from $-120{ }^{\circ} \mathrm{C}$ to $+215^{\circ} \mathrm{C}$.[16] Thermal development testing of the NEXT Prototype Model-1 (PM1) was conducted to assist in developing and validating a thruster thermal model and assessing the thermal design margins.[17] An ion thruster thermal model has been developed for the latest PM design to aid in predicting thruster temperatures for various missions. This model has been correlated with a thermal development test on the NEXT PM1 thruster with most predicted component temperatures within $5-10{ }^{\circ} \mathrm{C}$ of test temperatures.[18] The reworked PM thruster (designated PM1R) was subjected to the series of qualification-level environmental tests as shown in Figure 3. Post-test performance assessment test and inspection have shown that thruster performance was nominal and unchanged throughout the test and at post-test conditions, which completes environmental test validation of the PM thruster.[16] 


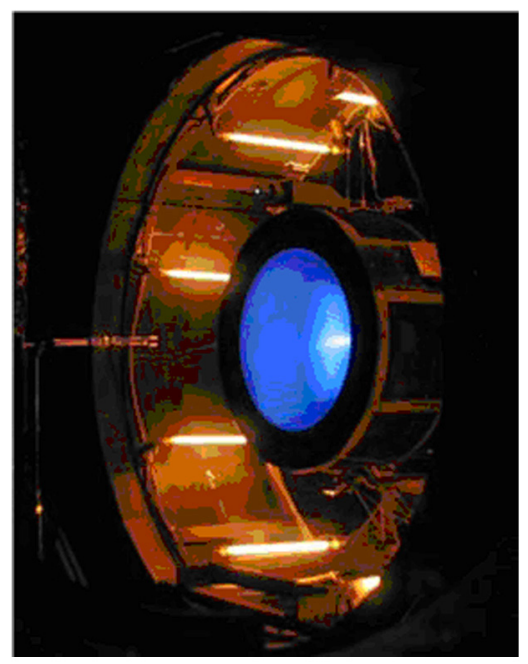

Figure 3 - NEXT PM1R Environmental Test.

The NEXT Engineering Model PPU was a modular design capable of very efficient operation through a wide voltage range because of innovative features like dual controls, module addressing, and a high current mode. The highly modular construction of the PPU resulted in improved manufacturability, simpler scalability, and lower cost relative to Dawn designs. The performance was measured in benchtop tests to range from 94.1 to $82.6 \%$.[19]

The EM Propellant Management System (PMS) delivers low pressure gas to the thruster from a supercritical xenon supply source, and it consists of a High Pressure Assembly (HPA) and a Low Pressure Assembly (LPA).[8] The PMS provides independent xenon flow control to the thruster main discharge, and discharge and neutralizer cathodes. Aerojet completed manufacturing of the EM PMS elements, including 2 HPAs (one flight-like) and 3 LPAs (one-flight like). All assemblies have completed functional testing, and both flight-like HPA and LPA assemblies successfully completed qualification-level vibration and thermal vacuum testing.

Other components under development include high voltage isolators, and heaters. The high-voltage isolator has been undergoing a life test to quantify leakage currents at full voltage to verify operation of this component over anticipated life. To date the NEXT isolators have accumulated over 20,000 hours of operation. Measurements indicate a negligible increase in leakage current during the test. Cyclic testing of multiple heaters was initiated to validate these modified fabrication processes while retaining high reliability heaters. Multiple heaters have been cycled to failure giving a service life twice that established for qualification space station plasma contactor heaters.[20]

A multi-thruster array test (MTAT) was beneficial to address thruster and gimbal-specific questions that drive the configuration of the IPS components as shown in Figure 4. This MTAT utilized multiple engineering model (EM)
NEXT ion thrusters as well as laboratory power consoles and laboratory propellant feed systems to operate multiple thrusters simultaneously. The engineering demonstration portion of MTAT[21] focused on the characterization of performance and behavior of the individual thrusters and the array as affected by the simultaneous operation of multiple ion thrusters. The MTAT physics effort focused on the characterization of the plasma environment generated by the simultaneous operation of multiple ion thrusters. The interaction of this plasma environment with the spacecraft and the thrusters themselves plays an important role in the determination of spacecraft configuration, acceptable array operating condition, and array lifetime. Published papers document ion beam characterization,[22] array local plasma,[23] electron flowfield characteristics of the plume,[24] and neutralizer coupling characteristics.[25]

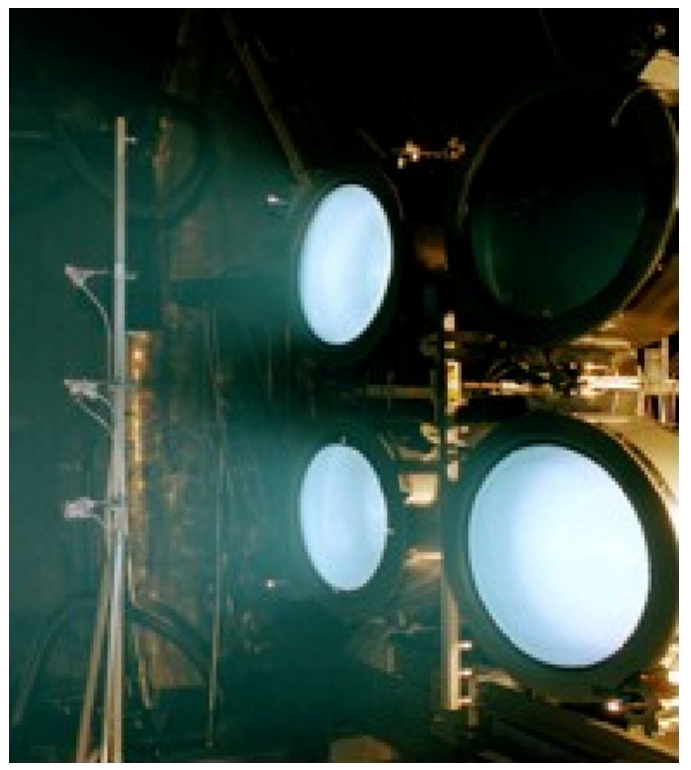

Figure 4 - NEXT Multi-Thruster Array Test.

A System Integration Test has been completed in which the PM thruster, EM PPU, EM PMS, and DCIU simulator were operated together in a single-string configuration. The purpose of the test is to demonstrate functionality and characterize operational capabilities of a complete string of NEXT components. The single-string configuration was operated over 17 throttle points to demonstrate compatibility of the individual components over the range of operating conditions. A multi-thruster configuration was operated to demonstrate compatibility of the PMS. Results of both tests are undergoing a thorough review and analysis prior to conducting a project review.

\section{Future Plans}

NEXT project activities have brought next-generation ion propulsion technology to a mature state, with existing tasks completing the majority of the NEXT product technology validation. Functional and qualification-level environmental tests of the EM PPU are anticipated in early FY09. The 
thruster life test will continue to accumulate additional throughput on the EM hardware to the project goal of 450 $\mathrm{kg}$ and beyond. A Project Validation Review will be conducted at the conclusion of Phase 2 in 2009, during which implementation risks will be identified and prioritized. A framework for that review has been published,[26] which provides the Technology Readiness Level (TRL) definitions, hardware maturity, and relevant environment definition. Residual project funding will be used to continue to buy down first user risks and costs.

\section{High Voltage Hall Accelerator (HIVHAC) THRUSTER}

\section{Description}

The recent focus of the HIVHAC thruster development task has been to develop a $3.5 \mathrm{~kW}$ Hall thruster with increased specific impulse, throttle-ability and lifetime to make Hall propulsion systems applicable to deep space science missions. The primary application focus for the resulting Hall propulsion system would be cost-capped missions.[27] The project is led by NASA's GRC teamed with Aerojet, JPL and the University of Michigan. The needs of many targeted robotic science missions exceed the throughput capability achievable without advanced development. Several different approaches to increasing HIVHAC propellant throughput have been evaluated. The thruster development goals will be achieved through a novel approach of using a channel replacement mechanism to mitigate the primary wear mechanism.

This throughput capability must be achieved at a discharge voltage of 700 Volts. The high voltage operation allows the thruster to operate at specific impulses much higher than conventional Hall thrusters. The high voltage also allows the thruster to operate at a much higher power density than conventional Hall thrusters. A comparison of the HIVHAC thruster to a conventional, SOA Hall thruster is shown in Table 2. A laboratory-model thruster has been fabricated and demonstrated critical functionality to proceed into the engineering model development phase.

Table 2. Performance Characteristics of HIVHAC vs. SOA Hall (SPT-100).

\begin{tabular}{|l|c|c|}
\hline \multicolumn{1}{|c|}{ Characteristic } & HIVHAC & SOA Hall \\
\hline Thruster Power Range, $\mathrm{kW}$ & $0.3-3.6$ & 1.4 \\
\hline Throttle Ratio & $12: 1$ & $1: 1$ \\
\hline Operating Voltage, V & $200-700$ & 300 \\
\hline Specific Impulse, sec & $1000-2800$ & 1450 \\
\hline Thrust, mN & $24-150$ & 79.8 \\
\hline Specific Mass, kg/kW & 2.3 & 4 \\
\hline Propellant Throughput, kg & $>300$ & 150 \\
\hline
\end{tabular}

The Advanced State-of-Art (ASOA) HIVHAC thruster development approach was a less traditional approach to extending thruster lifetime with the potential of enabling lifetimes in excess of 15,000 hours and throughputs in excess of $300 \mathrm{~kg}$. An ASOA laboratory-model thruster designed to provide a $300 \mathrm{~kg}$ throughput and shown in Figure 5 has been fabricated and has been under test to confirm this capability.

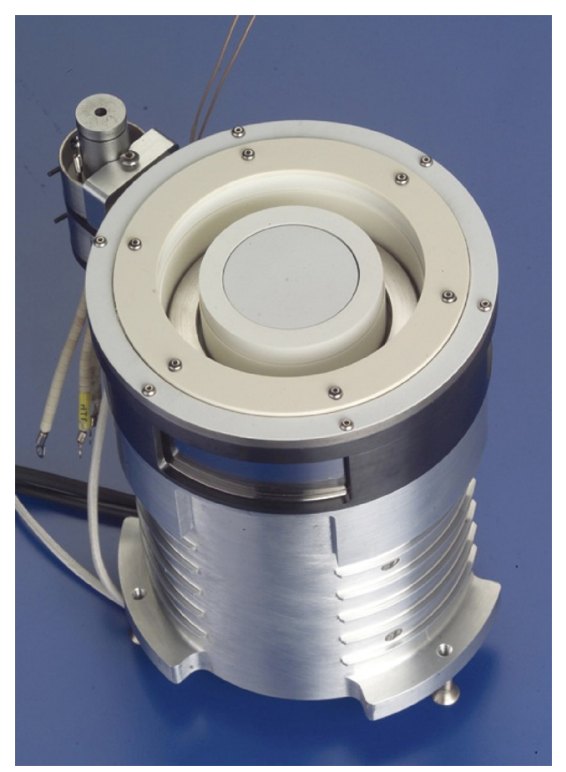

Figure 5 - HIVHAC laboratory thruster

\section{Recent Progress}

Wear tests have focused on collecting experimental data to validate numerical simulation of the discharge channel erosion. Test priorities have focused on the wear test of the laboratory thruster to demonstrate throughput capabilities of the design. In wear tests the thruster discharge channel profile is measured by laser profilometry prior to thruster installation. The thruster is operated for a given test period and removed from the test chamber to measure changes to the discharge chamber profile. The thruster, shown in Figure 6, has been operated in excess of 4700 hours $(100 \mathrm{~kg}$ of xenon throughput) as of September 30, 2008 and is projected to provide the predicted xenon throughput.[28] The thruster has demonstrated a throttle range of 12:1 and a maximum nominal power of $3.5 \mathrm{~kW}$. At $3.5 \mathrm{~kW}$ the thruster has demonstrated a performance of $55 \%$ total efficiency and 2780 seconds total impulse, and a predicted lifetime exceeding 15,000 hours.[29] The HIVHAC effort has proceeded with the engineering model design.[30] A Preliminary Design Review (PDR) was completed in August 2008. The review covered design requirements, design analysis, manufacturing and test plans, budget and schedule resources and risks. Design modifications identified during the PDR were implemented and component manufacturing has been initiated. 


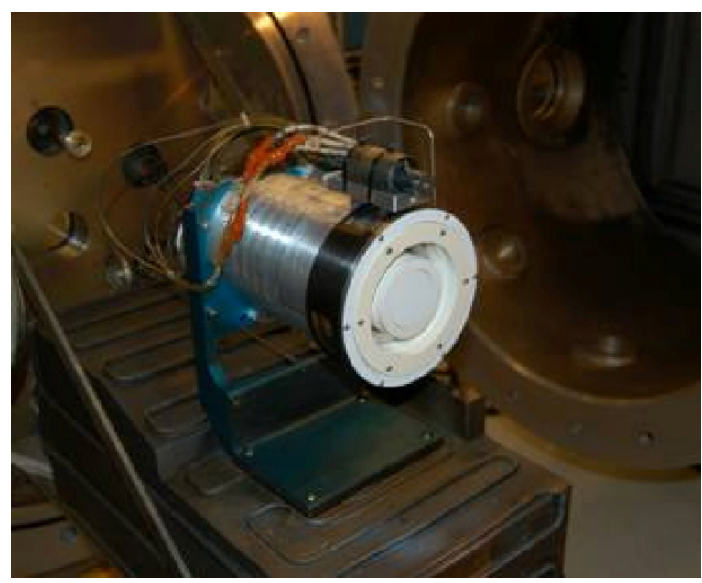

Figure 6-HIVHAC thruster installed for extended wear test

Concurrent with the wear test activity is a hollow cathode development activity aimed at providing a hollow cathode that operates in spot mode with minimal propellant and power consumption while producing the required life. A variety of cathode configurations were built and evaluated. The variations included studying the effects of cathode orifice plate throat length, emitter inner diameter, keeper plate orifice diameter, and cathode-keeper gap on hollow cathode performance and operation. Results indicated that changes to the cathode-keeper gap had the most profound effect on stable cathode operating conditions.[31]

\section{Future Plans}

EM thruster fabrication and assembly will continue in FY09. The delivery of the first EM thruster is anticipated in May 2009, which will proceed EM thruster testing. EM thruster testing will include performance acceptance tests, a full suite of environmental tests, and a long duration test.

\section{Advanced Xenon Feed System (AXFS)}

\section{Description}

The Advanced Xenon Feed System (AXFS) task was funded to develop feed system components based on a novel diffusion bonding manufacturing technique. The task has been led by VACCO Industries and seeks to improve the reliability of electric propulsion feed systems while decreasing mass and volume over conventional xenon feed system technologies.

To improve reliability, the entire system is both series and parallel redundant as shown in Figure 7. An initial study of the reliability analyses completed at a component level has shown this configuration to have an expected lifetime approaching 30 years; exceeding all mission requirements. The mass of the proposed system is also substantially lower than conventional technologies. The Flow Control Module (FCM) has a mass of 650 grams and the Pressure Control Module (PCM) has a mass less than 730 grams. A three thruster system has an estimated mass of $2.71 \mathrm{~kg}$ or an $80 \%$ mass reduction over conventional technologies.

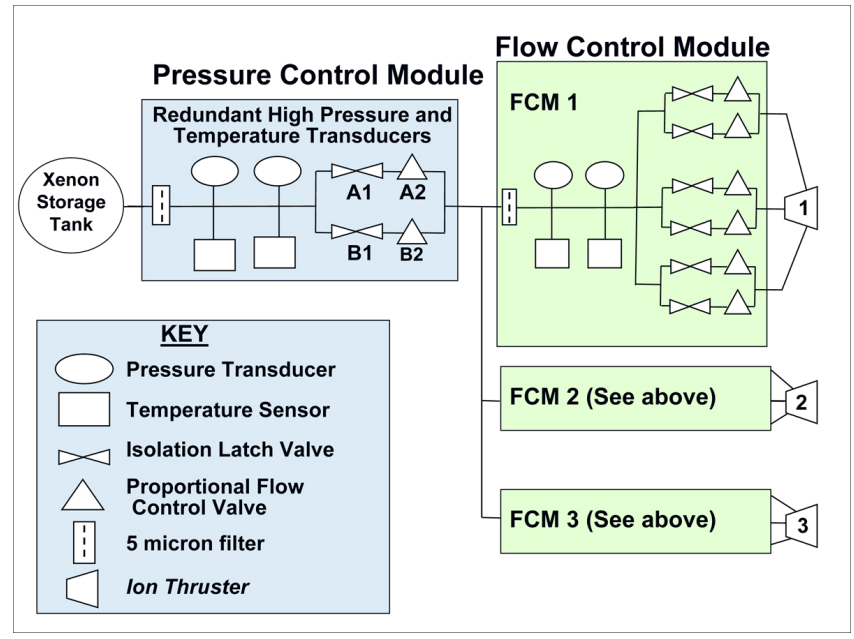

Figure 7 - Advanced Xenon Feed Sysstem Configuration

\section{Recent Progress}

Following a user requirements definition study early in the base phase, the conceptual feed system architecture was changed from a digital fuel control array to an architecture that utilizes piezoelectrically actuated proportional micro valves to meet flow accuracies and reliability requirements while maintaining reduced mass and volume. VACCO has leveraged IR\&D funds to develop the proportional micro valves. These valves along with latch valves and micro pressure and temperature sensors have been integrated into a diffusion-bonded Flow Control Module (FCM) as shown in Figure 8. Two FCMs have been delivered to NASA in June 2007 with one unit tested in relevant environmental conditions, such as thermal, vibration, and shock environments.

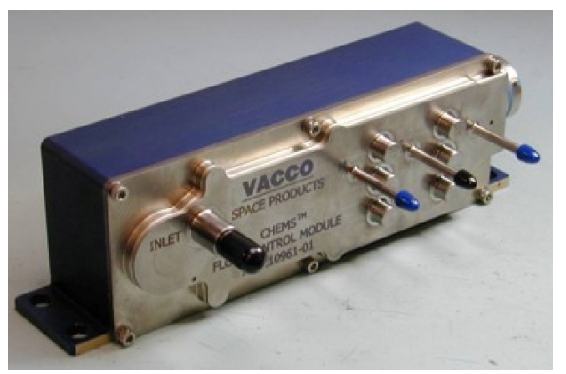

Figure 8 - Flow Control Module

A follow-on contract was awarded to VACCO in August 2007, which funded the development of the AXFS controller, fabrication and testing of a Pressure Control Module (PCM), integrating the system with an FCM, and end-to-end system testing of these components with an ion thruster. The PCM design and fabrication were completed with hardware acceptance testing completed in August 2008. Benchtop functionality and environmental tests were completed at the Naval Research Laboratory (NRL) in 
September 2008. The completion of environmental testing brought the component to a TRL- 6 status.

\section{Future Plans}

The FCM and PCM have been assembled into a two-stage AXFS configuration for additional tests. The first vacuum operation of the assembled AXFS configuration is anticipated in November 2008. After completion of vacuum functionality and calibration, the unit will be operated in a "hot-fire" integration test with a NEXT EM thruster, which is anticipated by early 2009 .

\section{STANDARD ARCHitecture}

\section{Description}

Standard Architecture is a design philosophy, which focuses on reducing first user costs through a simplified thruster string design that provides required system redundancy by including one additional thruster string. In addition Standard Architecture promises to reduce non-recurring, first-user costs by investing in cross-platform design solutions to components such as the DCIU, PPU and feed systems, when it is applicable and beneficial to performance and cost. Standard Architecture is led by JPL with contributions by GRC.

\section{Recent Progress}

A study investigated several PPU designs for compatibility with multiple thruster designs. A comparison of engineering specifications to thruster operating parameters was completed. In addition the degree of difficulty to modify the various PPUs to operate thrusters of interest was assessed. The results of the study indicate that the NEXT PPU design was the best candidate for cross-platform operation based on demonstrated operation as well as ease of design modifications and cost effectiveness to achieve full compatibility with both NEXT and SOA ion thrusters.

Another cost savings approach investigated and pursued is the integration of the DCIU into the PPU of an ion propulsion system. The addition of one control card in the PPU eliminates the need for a separate box and the associated qualification costs. The practice is common in hall propulsion systems, but has not been fully adopted by the ion propulsion community to date.

Cross-platform design solutions are being investigated for the DCIU and feed system components. Simplifications to feed system design reflect the recent practices by industry, such as usage of high-pressure regulators in commercial xenon feed systems. A brassboard model DCIU is being designed to operate with the proposed feed system. The design will leverage Dawn heritage hardware and software.

\section{Future Plans}

The on-going tasks for the feed system and DCIU development will be completed in 2009. The DCIU development task includes definition of requirements for performance and interfaces, design of hardware and software, fabrication and testing of the brassboard DCIU and documentation. The feed system task includes development of requirements for performance and interfaces, hardware design, hardware assembly for testing and documentation. The results from these tasks will be available to all users for incorporation in future EM designs. The completion of these tasks will conclude all investments and activities in Standard Architecture due to the lack of sufficient resources.

\section{CONClusions}

Major hardware development tasks within the In-Space Propulsion Technology Project include NEXT Ion Propulsion System, HIVHAC Hall thruster, and VACCO xenon feed system. The NEXT system consists of a highperformance, $7-\mathrm{kW}$ ion thruster; a high-efficiency, 7-kW power processor unit; a highly flexible advanced xenon propellant management system; a lightweight engine gimbal; and key elements of a digital control interface unit, including software algorithms. NEXT project activities have brought next-generation ion propulsion technology to a mature state, with existing tasks completing the majority of the NEXT product technology validation. Functional and qualification-level environmental tests of key system components are anticipated to be completed in the near future. The HIVHAC task is meeting its goals of advancing the Hall thruster technology readiness for science mission applications. The task seeks to increase specific impulse, throttle-ability and lifetime to make Hall propulsion systems applicable to deep space science missions. The HIVHAC thruster has demonstrated a throttle range of 12:1 and a maximum nominal power of $3.5 \mathrm{~kW}$. At $3.5 \mathrm{~kW}$ the thruster has demonstrated a performance of 55\% total efficiency and 2780 seconds total impulse, and a predicted lifetime exceeding 15,000 hours. An advanced xenon feed system task has developed feed system components based on a novel diffusion bonding manufacturing technique. The task has been led by VACCO Industries and seeks to improve the reliability of ion propulsion feed systems while decreasing mass and volume over SOA xenon feed system technologies. Standard Architecture tasks are developing cross-platform components and simplified designs to reduce first user costs and will be completed in FY09. Efforts under each of the development tasks focus on advancing technology readiness for flight infusion.

\section{ACKNOWLEDGMENTS}

The author would like to acknowledge the support of the InSpace Propulsion Technology Project managed by the NASA Glenn Research Center for the Science Mission Directorate. 


\section{REFERENCES}

[1] NASA Science Plan 2007, http://science.hq.nasa.gov/strategy/Science_Plan_07.pdf

[2] Kremic, T., Anderson, D., and Dankanich, J., "NASA's In-Space Propulsion Technology Project Overview and Mission Applicability”, 2008 IEEE Aerospace Conference, IEEEAC Paper \#1481, Big Sky, MT, March 2008.

[3] Dankanich, J., "In-Space Propulsion Electric Propulsion Technologies Mission Benefits," 2008 IEEE Aerospace Conference, IEEEAC Paper \#1480, Big Sky, MT, March 2008.

[4] Rayman, M., Fraschetti, T., Raymond, C., and Russell, C., "Dawn: A Mission in Development for Exploration of Main Belt Asteroids Vesta and Ceres", 55th International Astronautical Congress, Paper \# IAC-04-Q.5.05, Vancouver, Canada, October 2004.

[5] Patterson, M. and Benson, S., Soulas, G., "NEXT Ion Propulsion System Development Status", Proceedings of 54th JANNAF Propulsion Meeting, Orlando, FL, December 2008.

[6] Benson, S., Riehl, J., Oleson, S., "NEXT Ion Propulsion System Configurations and Performance for Saturn System Exploration", AIAA-2007-5230, 43rd Joint Propulsion Conference, Cincinnati, OH, July 2007.

[7] Monheiser, J., Aadland, R. and Wilson, A., "Development of a Ground Based Digital Control Interface Unit (DCIU) for the NEXT Propulsion System," AIAA-2004-4112, 40th Joint Propulsion Conference, Fort Lauderdale, FL, July 2004.

[8] Aadland, R., Monheiser, J., Driscoll, E., Wilson, F., Benson, S., "Development Status of NEXT Propellant Management System," AIAA-2004-3974, 40th Joint Propulsion Conference, Fort Lauderdale, FL, July 2004.

[9] Herman, D., Soulas, G. and Patterson, M. "Performance Evaluation of the 40-cm NEXT Prototype Model Ion Thruster", AIAA-2007-5212, 43rd AIAA/ASME/SAE/ASEE Joint Propulsion Conference and Exhibit, Cincinnati, OH, July 2007.

[10] Soulas, G., Patterson, M. Van Noord, J., "NEXT Ion Thruster Performance Dispersion Analyses", AIAA-20075213, 43rd AIAA/ASME/SAE/ASEE Joint Propulsion Conference and Exhibit, Cincinnati, OH, July 2007.

[11] Van Noord, J. and Williams, G., "Lifetime Assessment of the NEXT Ion Thruster", AIAA-2007-5274, 43rd AIAA/ASME/SAE/ASEE Joint Propulsion Conference and Exhibit, Cincinnati, OH, July 2007.
[12] Van Noord, J., Herman, D., "Application of the NEXT Ion Thruster Lifetime Assessment to Thruster Throttling", AIAA-2008-4526, 44th AIAA/ASME/SAE/ASEE Joint Propulsion Conference and Exhibit, Hartford, CT, July 2008.

[13] Herman, D., Soulas, G., and Patterson, M., "Status of the NEXT Ion Thruster Long-Duration Test", AIAA-20075272, 43rd AIAA/ASME/SAE/ASEE Joint Propulsion Conference and Exhibit, Cincinnati, OH, July 2007.

[14] Herman, D., Soulas, G., Patterson, M., "Performance Characteristics of the NEXT Long-Duration Test after $16,550 \mathrm{~h}$ and $337 \mathrm{~kg}$ of Xenon Processed," AIAA-20084527, 44th AIAA/ASME/SAE/ASEE Joint Propulsion Conference and Exhibit, Hartford, CT, July 2008.

[15] Herman, D., Soulas, G., Patterson, M., "NEXT LongDuration Test Plume and Wear Characteristics after $16,550 \mathrm{~h}$ of Operation and $337 \mathrm{~kg}$ of Xenon Processed," AIAA-2008-4919, 44th AIAA/ASME/SAE/ASEE Joint Propulsion Conference and Exhibit, Hartford, CT, July 2008.

[16] Snyder J., Anderson, J., Soulas, G., Van Noord, J., "Environmental Testing of the NEXT PM1R Ion Engine", IEPC-2007-276, 30th International Electric Propulsion Conference, Florence, Italy, September 2007.

[17] Anderson, J., Snyder, J., Van Noord, J., and Soulas, G., "Thermal Development Test of the NEXT PM1 Ion Engine", AIAA-2007-5217, 43rd AIAA/ASME/SAE/ASEE Joint Propulsion Conference and Exhibit, Cincinnati, OH, July 2007.

[18] Van Noord, J., "NEXT Ion Thruster Thermal Model", AIAA-2007-5218, 43rd AIAA/ASME/SAE/ASEE Joint Propulsion Conference and Exhibit, Cincinnati, OH, July 2007.

[19] Pinero, L., Todd, P. and Hopson, M. "Integration and Qualification of the NEXT Power Processing Unit", AIAA-2007-5214, 43rd AIAA/ASME/SAE/ASEE Joint Propulsion Conference and Exhibit, Cincinnati, OH, July 2007.

[20] Herman, D., Pinero, L., Sovey, J., "NASA's Evolutionary Xenon Thruster (NEXT) Component Verification Testing," AIAA-2008-4812, 44th AIAA/ASME/SAE/ASEE Joint Propulsion Conference and Exhibit, Hartford, CT, July 2008.

[21] Patterson, M., Foster, J., McEwen, H., Pencil, E., Van Noord, J. and Herman, D., "NEXT Multi-Thruster Array Test - Engineering Demonstration," AIAA-2006-5180, 42nd Joint Propulsion Conference, Sacramento, CA, July 2006. 
[22] Pencil, E., Foster, J., Patterson, M., Van Noord, J., McEwen, H., Diaz, E., "Ion Beam Characterization of the NEXT Multi-Thruster Array Plume,” AIAA-2006-5182, 42nd Joint Propulsion Conference, Sacramento, CA, July 2006.

[23] McEwen, H., Foster, J., Pencil, E., Patterson, M., Diaz, E. and Van Noord, J., "Characterization of Plasma Flux Incident on a Multi-Thruster Array, " AIAA-2006-5183, 42nd Joint Propulsion Conference, Sacramento, CA, July 2006.

[24] Foster, J., Patterson, M., Pencil, E., McEwen, H., Diaz, E. and Van Noord, J., "Plasma Characteristics Measured in the Plume of a NEXT Multi-Thruster Array," AIAA2006-5184, 42nd Joint Propulsion Conference, Sacramento, CA, July 2006.

[25] Foster, J., Pencil, E., McEwen, H. Patterson, M., Diaz, E. and Van Noord, J., "Neutralizer Plasma Coupling in a NEXT Multi-Thruster Array," AIAA-2006-5184, 42nd Joint Propulsion Conference, Sacramento, CA, July 2006.

[26] Benson, S., Patterson, M., Snyder, J., "NEXT Ion Propulsion System Progress Towards Technology Readiness," AIAA-2008-5285, 44th AIAA/ASME/SAE/ASEE Joint Propulsion Conference and Exhibit, Hartford, CT, July 2008.

[27] Kamhawi, H., Manzella, D. Mathers, A., Aadland, R., "In-Space Propulsion High Voltage Hall Accelerator Project Overview," Proceedings of 54th JANNAF Propulsion Meeting, Orlando, FL, December 2008.

[28] Kamhawi, H. Manzella, D., "High Voltage Hall Accelerator Wear Test Update," Proceedings of 54th JANNAF Propulsion Meeting, Orlando, FL, December 2008.

[29] Peterson, P., Kamhawi, H., Manzella, D., and Jacobson, J., "Hall Thruster Technology for NASA Science Missions: HiVHAC Status Update", AIAA-2007-5236, 43rd AIAA/ASME/SAE/ASEE Joint Propulsion Conference and Exhibit, Cincinnati, OH, July 2007.

[30] Mathers, A., Aadland, R., Manzella, D., Kamhawi, H., "Development Status of the HIVHAC Hall Thruster," AIAA-2008-4524, 44th AIAA/ASME/SAE/ASEE Joint Propulsion Conference and Exhibit, Hartford, CT, July 2008.

[31] Kamhawi, H., "Various Hollow Cathode Configurations Testing for the High Voltage Hall Accelerator" AIAA2007-5172, 43rd AIAA/ASME/SAE/ASEE Joint Propulsion Conference and Exhibit, Cincinnati, OH, July 2007.

\section{BIOGRAPHY}

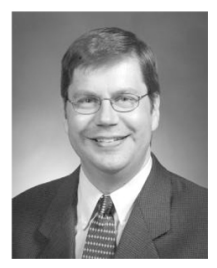

Eric Pencil is the Electric Propulsion Projects Manager for the In-Space Propulsion Technology Office at NASA Glenn Research Center. He is responsible for the management and execution of the electric propulsion development tasks for NASA Science missions. Previous to taking this position he was a project/research engineer in the electric propulsion research group in which he worked on various electric propulsion technologies at varying stages of maturity from basic research to flight hardware. 